\title{
THE ACIDOSIS INDEX
}

\author{
A CLINICAL MEASURE OF THE DEgREE OF ACIDOSIS
}

T. STUART HART, M.D.

NEW YORK

The detection of a condition of acidosis is usually a simple matter. The quantitative determination of the degree of acidosis, while most important from the clinical standpoint, is often neglected on account of the difficult and time-consuming procedures necessary to obtain accurate information.

\section{METHODS OF ESTIMATING THE DEGREE OF ACIDOSIS}

The degree of acidosis may be determined in several ways. For the purpose of the present discussion, only those methods are considered which have for their object the determination of those forms of acidosis due to the presence of the acetone bodies, seen in their most severe types in diabetes mellitus.

1. The method of Stadelmann, ${ }^{1}$ a classical chapter in the history of the discovery of the abnormal production of organic acids in diabetes, depends on the quantitative estimation of the bases (sodium, potassium, calcium, magnesium and ammonium) and of the inorganic acids of the urine. When organic acids are being excreted, it is found that the amount of bases excreted is in excess of the amount necessary to combine with the estimated inorganic acids. This excess of bases is excreted in combination with organic acids and therefore furnishes data upon which one may accurately estimate the amount of organic acids being eliminated. While this method is of great value, the amount of time required makes its employment prohibitive in ordinary clinical work.

2. Perhaps the most satisfactory procedure is the direct quantitative estimation of acetone and diacetic acid by the method of Messinger, as modified by Huppert, or by the method of Hart, ${ }^{3}$ combined with the estimation of oxybutyric acid by the method of Shaffer ${ }^{4}$ or of Black. ${ }^{5}$ These determinations give us most satisfactory direct information as to the degree of acidosis, but in turn must be discarded in clinical work on account of the time, skill, and facilities required for their execution.

1. Stadelmann: Areh. f. exper. Path. u. Pharmakol., 1883, xvii, 419.

2. Messinger: Analyse des Harns, 1898.

3. Hart: Jour. Biol. Chem., 1908, iv, 477.

4. Shaffer: Jour. Biol. Chem., 1908, v, 211.

5. Black: Jour. Biol. Chem., 1908, v, 207. 
3. The levo-rotary properties of beta-oxybutyric acid make possible its quantitative determination by means of the polariscope, and while this gives us information of significant value, it is not a method of great accuracy and is one which can be used only with careful technic and a considerable expenditure of time.

4. Since the recognition of the fact that the organism protects itself from its excess of organic acids by the production of increased amounts of ammonia, the quantity of the ammonia excreted has been utilized to estimate the extent of the acidosis. The quantitative estimation of ammonia gives us much important information, not only as regards the degree of acidosis, but also as regards the effect of the therapeutic administration of alkalis, and its determination by Folin's ${ }^{6}$ method is so simple and accurate that this should be a routine procedure in every advanced case of acidosis. One should, however, interpret the ammonia findings with due reference to the facts which are known to effect variations in its production, especially that it is regularly augmented on a diet rich in protein, and is produced in increased amounts for the purposes of neitralizing acids only when these acids are not already satisfied by the bases furnished by the body or taken in as food or medication. It is therefore evident that during the administration of alkalis the ammonia ontput is not a measure of the quantity of organic acids being excreted.

\section{NEW CLINICAL METHOD}

Several years ago I proposed a simple test-tube method for estimating the degree of acidosis in cases of moderate severity. I have used this with considerable satisfaction in following cases with the production of small amounts of acetone and diacetic acid, and I have sought to extend its usefulness by devising a simple method which should give us a rough clinical idea of the daily fluctuations of the organic acid output in cases of severe acidosis.

It should be clearly stated at the outset that there is no claim that this method accurately estimates the quantitative excretion of the acetone bodies. It does, however, afford real information in regard to the fluctuation of the total acidosis from day to day; it is certainly simpler and probably more accurate than the measure of acidosis which we obtain with the polariscope; and while it does not replace the information afforded by the determination of ammonia, it is of considerable value as a complement to this, especially when alkalis are being administered. In regard to all these points $I$ hope to submit satisfactory proof.

6. Folin: Ztschr. f. physiol. Chem., 1902, xxxvii, 161.

7. Hart, T. S.: A Contribution to Our Knowledge of the Acetone Bodies, with a Clinical Method for the Quantitative Estimation of Diacetic Acid and Acetone, The Archives Int. Med., 1908, i, 218. 
The method depends on the intensity of the color developed by adding ferric chlorid to urine containing the acetone bodies (Gerhardt's reaction). The solutions necessary are:

1. The "standard solution," consisting of ethyl acetate, 1 c.c.; alcohol, 25 c.c.; and distilled water to 1,000 c.c.

2. Ferric chlorid solution, consisting of $100 \mathrm{gm}$. of ferric chlorid dissolved in 100 c.c. of distilled water.

Take two test-tubes of equal caliber (one-half inch in diameter), put in one 10 c.c. of the "standard solution," and in the other 10 c.c. of the urine to be tested, add to each 1 c.c. of the ferric chlorid solution, allow the tubes to stand for a couple of minutes to permit the color to develop fully, and then compare the color of the two test-tubes when they are held between the eye and the sky. If the tube containing the "standard solution" is of a lighter shade than the urine mixture, dilute this with distilled water until the colors match, noting the volume to which it has been necessary to dilute the urine mixture.

By this means we obtain what we may call the "acidosis index per. liter" in accordance with the following schedule:

Volume of Urine Solution.

10 c.c.

15 c.c.

20 c.c.

25 c.c.

40 c.c.

100 c.c.

$\begin{array}{cc} & \text { Acidosis Index per Liter. } \\ \equiv & 1 \\ \equiv & 1.5 \\ \equiv & 2 \\ \equiv & 2.5 \\ \equiv & 4 \\ \equiv & 10\end{array}$

(Intermediate volumes have a proportional index).

In order to obtain the "acidosis index" proper, we multiply the value of the "acidosis index per liter" by the amount of urine in liters passed in twenty-four hours.

For example: A patient passed 3,200 c.c. urine in twenty-four hours; when 10 c.c. of this was treated as described above, it was found necessary to dilute this to 75 c.c. in order to match the standard; his "acidosis index per liter" was therefore 7.5 and his "acidosis index" was $\% .5$ times $3.2=24$.

\section{MATERIAL}

This paper is based on observations made on forty-one cases of acidosis, varying in intensity from the mildest grades to those of extreme acid intoxication. By far the greater part were diabetics, but a few others have been included, viz., starvation, obesity, carcinoma of the stomach, febrile and post-operative cases. The material was drawn almost entirely from private practice, only a few hospital cases have been included. The patients were observed for varying periods, some seen in consultation were observed but once, while others have been followed personally for five or six years. The maximum number of observations made on a single case was 63 . 


\section{EVIDENCE OF THE VALUE OF THE ACIDOSIS INDEX FOR ESTIMATING ORGANIC ACID ELIMINATION}

In Table 1 is presented the record of a patient suffering from severe progressive diabetes terminating in coma July 6, 1909, who was seen at intervals for a considerable period.

I would call attention to the parallelism which exists between the degree of acidosis as estimated by the polariscope and the "acidosis index." This is shown graphically in Chart 1, which has been plotted from the values of Table 1. It will be noticed that the rise and fall of the two curves is very similar in direction, notwithstanding the fact that the curves tend to diverge in the higher values. This point will be referred to later.

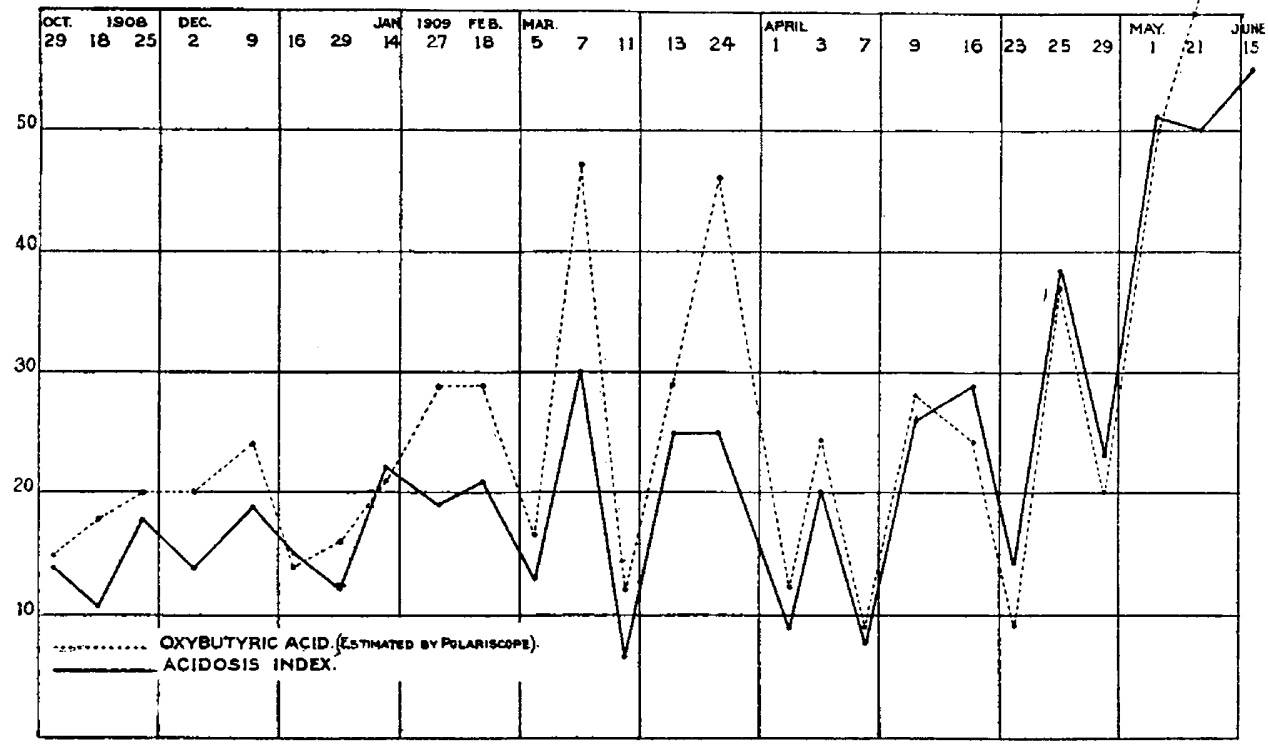

Chart 1.-Curve of oxybutyric acid estimated by polariscope, and acidosis index plotted from record of diabetic patient (Table 1).

Chart 2 is also plotted from Table 1. Here are compared the curves of the ammonia output and the "acidosis index." For this comparison only those days were selected from Table 1 on which the patient was taking no alkali, as on these occasions the ammonia more nearly represents the degree of acidosis.

Table 2 records the events of a severe diabetes in a boy aged 12 ; only those days are recorded on which no alkali was taken; this patient is still under occasional observation. Chart 3 is plotted from this record and shows a comparison of the curves of the ammonia output and the "acidosis index." 
Cases of this kind could be multiplied, but they all show a very definite parallelism in the curves of the "acidosis index" and those of the acidosis estimated by the polariscope, and as calculated on the ammonia output.

In Table 3 will be found the record of the final month of a case of diabetes ending in collapse. In this case for a considerable period the total acidosis was accurately determined ${ }^{8}$ by the method of Shaffer.

In Chart 4 the same case is recorded graphically. Here the ammonia curve is omitted, as this was modified by the administration of varying amounts of bicarbonate of soda by mouth and by infusion.

Table 1.-Record of a Diabetic Patient

\begin{tabular}{|c|c|c|c|c|c|}
\hline \multirow[b]{2}{*}{ Date. } & \multirow{2}{*}{$\begin{array}{l}\text { Urine } \\
\text { Quantity } \\
\text { c.e. }\end{array}$} & \multicolumn{3}{|c|}{$\begin{array}{l}\text { Oxybutyric } \\
\text { Acid. Estimated } \\
\text { by Polariza- }\end{array}$} & \multirow{2}{*}{$\begin{array}{c}\text { Bicarbonate } \\
\text { s of Sodaa } \\
\text { gm. }\end{array}$} \\
\hline & & $\begin{array}{l}\text { Ammonia } \\
\text { gm. }\end{array}$ & 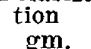 & $\begin{array}{l}\text { Acidosis } \\
\text { Index. }\end{array}$ & \\
\hline $10 / 29 / 08$ & 2,310 & $\cdots$ & 15 & 14 & 0 \\
\hline $11 / 10 / 08$ & 1,920 & $\ldots$ & & 10 & 0 \\
\hline $\mathrm{Il} / 18 / 08$ & 2,100 & $\ldots$ & 18 & 11 & 0 \\
\hline $11 / 25 / 08$ & 2,220 & $\ldots$ & 20 & 18 & 12 \\
\hline $12 / 2 / 08$ & 2,220 & $\ldots$ & 20 & 14 & 12 \\
\hline $12 / 9 / 08$ & 2,700 & $\ldots$ & 24 & 19 & 16 \\
\hline $12 / 16 / 08$ & 2,100 & & 14 & 15 & 0 \\
\hline $12 / 29 / 08$ & 2,400 & 3.284 & 16 & 12 & 0 \\
\hline $1 / 14 / 09$ & 3,195 & 1.711 & 21 & 22 & 45 \\
\hline $1 / 27 / 09$ & 2,670 & 6.038 & 29 & 19 & 0 \\
\hline $2 / 18 / 09$ & 2,610 & 4.748 & 29 & 21 & 45 \\
\hline $3 / 5 / 09$ & 2,550 & 4.487 & 17 & 13 & 0 \\
\hline $3 / 7 / 09$ & 3,030 & 3.757 & 47 & 30 & 45 \\
\hline $3 / 11 / 09$ & 1,770 & 2.798 & 12 & 7 & 0 \\
\hline $3 / 13 / 09$ & 2,190 & 2.420 & 29 & 25 & 45 \\
\hline $3 / 24 / 09$ & 4,200 & 5.790 & 46 & 25 & 0 \\
\hline $4 / 1 / 09$ & 1,770 & 3.490 & 12 & 9 & 0 \\
\hline $4 / 3 / 09$ & 2,700 & 5.449 & 24 & 20 & 0 \\
\hline $4 / 7 / 09$ & 2,060 & 4.132 & 9 & 8 & 0 \\
\hline $4 / 9 / 09$ & 2,130 & 3.349 & 28 & 26 & 45 \\
\hline $4 / 16 / 09$ & 3,630 & 1.388 & 24 & 29 & 45 \\
\hline $4 / 23 / 09$ & 4,020 & 3.140 & 9 & 14 & 0 \\
\hline $4 / 25 / 09$ & 4,260 & 4.092 & 37 & 38 & 45 \\
\hline $4 / 29 / 09$ & 4,590 & 4.760 & 20 & 23 & 0 \\
\hline $5 / 1 / 09$ & 4,620 & 4.673 & $5 \mathrm{I}$ & 51 & 45 \\
\hline $5 / 21 / 09$ & 4,560 & 5.889 & 60 & 50 & 45 \\
\hline $6 / 15 / 09$ & 5,450 & 6.152 & 96 & 55 & 60 \\
\hline
\end{tabular}

Table 2.-Record of Severe Diabetes in a Boy Aged 12

\begin{tabular}{|c|c|c|c|c|c|c|c|}
\hline Date. & $\begin{array}{l}\text { Urine } \\
\text { Quantity } \\
\text { c.c. }\end{array}$ & $\begin{array}{c}\text { Ammonia } \\
\text { gm. }\end{array}$ & $\begin{array}{l}\text { Acidosis } \\
\text { Index. }\end{array}$ & Date. & $\begin{array}{c}\text { Urine } \\
\text { Quantity } \\
\text { c.c. }\end{array}$ & $\underset{\mathrm{gm}}{\underset{\mathrm{gmmonia}}{ }}$ & $\begin{array}{c}\text { Acidosis } \\
\text { Index. }\end{array}$ \\
\hline $12 / 24 / 08$ & 1,920 & 1,882 & 6 & $4 / 17 / 09$ & 3,600 & 3,458 & 14 \\
\hline $1 / 16 / 09$ & 1,920 & 2.310 & 5 & $4 / 28 / 09$ & 1,920 & 2.778 & \\
\hline $1 / 29 / 09$ & 1,920 & 3.525 & 10 & $5 / 13 / 09$ & 1,920 & & 3 \\
\hline $2 / 11 / 09$ & 2,016 & 3.513 & 8 & $5 / 27 / 09$ & 2,400 & 3.958 & \\
\hline $2 / 26 / 09$ & 1,995 & 2.171 & 7 & $11 / 2 / 09$ & 4,440 & 4.151 & \\
\hline $3 / 12 / 09$ & 2,520 & 4.862 & 13 & $4 / 21 / 10$ & 5,760 & 7.056 & 3 \\
\hline $3 / 26 / 09$ & 2,490 & 3.259 & 12 & $5 / 28 / 10$ & 5,760 & 3.819 & 9 \\
\hline
\end{tabular}

8. I am indebted to Dr. H. O. Mosenthal for assistance in making a part of these analyses. 
Table 3.-Final Montil of a Case of Diabetes Ending in Collapse

\begin{tabular}{|c|c|c|c|c|c|c|}
\hline Date. & 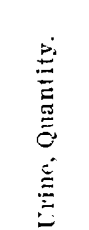 & 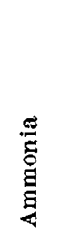 & 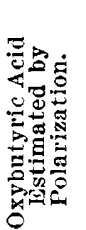 & 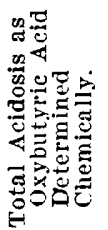 & 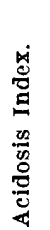 & 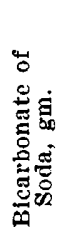 \\
\hline $11 / 30 / 08$ & $\begin{array}{r}\text { c.c. } \\
4,800\end{array}$ & $\begin{array}{c}\mathrm{gm} . \\
3.07\end{array}$ & $\begin{array}{l}\mathrm{gm} . \\
63\end{array}$ & $\begin{array}{c}\mathrm{gm} . \\
\ldots\end{array}$ & 58 & $\underset{60}{\mathrm{gm}}$. \\
\hline $12 / 2 / 08$ & 4,680 & 3.51 & 62 & $\ldots$ & 51 & 60 \\
\hline $12 / 6 / 08$ & 4,470 & 4.22 & 69 & & 47 & 24 \\
\hline $12 / 8 / 08$ & 4,050 & 3.90 & 62 & 38.13 & 36 & 50 \\
\hline $12 / 10 / 08$ & 3,150 & 3.24 & 55 & 24.67 & 30 & 25 \\
\hline $12 / 13 / 08$ & 2,040 & 1.89 & 31 & 21.25 & 20 & 25 \\
\hline $12 / 15 / 08$ & 1,800 & 3.35 & 24 & 16.11 & 16 & 0 \\
\hline $12 / 17 / 08$ & 1,800 & 3.59 & 20 & 16.40 & 14 & 0 \\
\hline $12 / 21 / 08$ & 2,310 & 4.02 & 36 & 17.73 & 17 & 10 \\
\hline $12 / 24 / 08$ & 2,550 & 4.45 & 28 & 19.27 & 20 & 10 \\
\hline $12 / 29 / 08$ & 3,360 & 3.55 & 15 & 12.70 & 13 & 5 \\
\hline
\end{tabular}

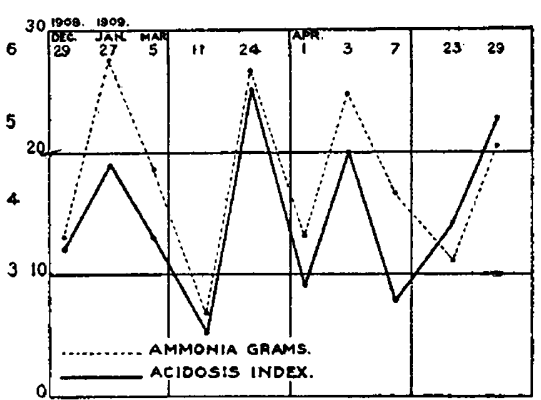

Chart 2.-Ammonia output and acidosis index, plotted from record of diabetic patient (Table 1).

It will be observed that there is a well-marked parallelism in the three curves. The similarity in the curves of the "acidosis index" and the total acidosis accurately estimated in grams of oxybutyric acid is extraordinary.

It is to be noted that while the parallelism of the three curves obtained by different methods is quite evident, the values estimated from the polariscopic readings are much too high, particularly in the larger amounts. This is entirely in harmony with the observations of Magnus Levy, ${ }^{9}$ who has pointed out that the polariscopic estimations of betaoxybutyric acid have given exaggerated values. This may explain the variations in the curves of Chart 1 , where the polariscopic estimations are relatively very high when the acidosis is high. For this reason, and on account of the fact that the "acidosis index" corresponds much better with the ammonia output (see Chart 2), I am inclined to think that the

9. Magnus-Levy: Arch. f. exper. Path. u. Pharmakol., 1899, xlii, 149. 


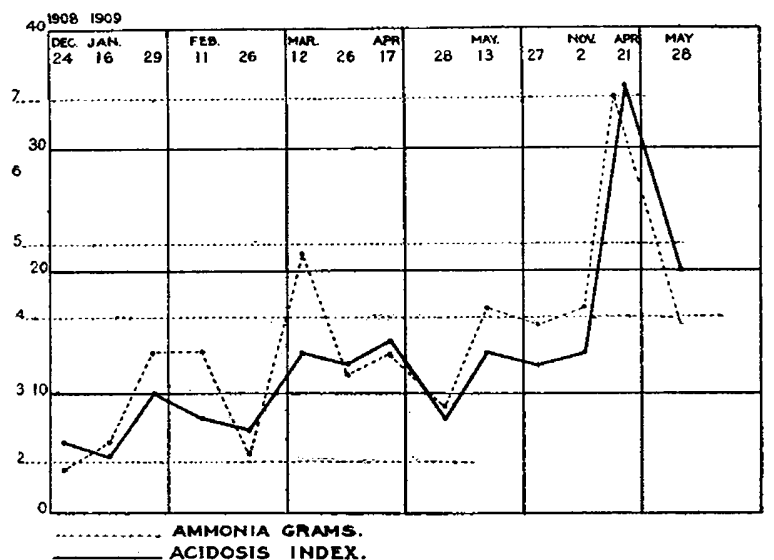

Chart 3.-Ammonia output and acidosis index, plotted from record of diabetic patient (Table 2).

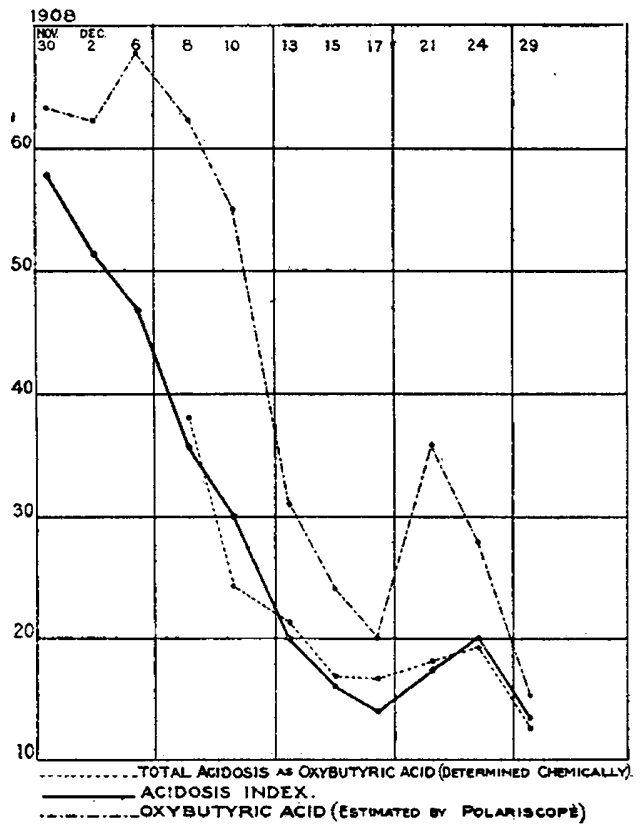

Chart 4.-Curves of total acidosis as oxybutyric acid (determined chemically), acidosis index and oxybutyric acid (estimated by polariscope), plotted from the record given in Table 3 of the final month of a case of diabetes ending in collapse. 
"acidosis index" represents the actual degree of acidosis much more accurately than the polariscopic determination.

The "acidosis index" is of considerable value in those cases in which alkali is being administered. On the alkali days the ammonia output is usually greatly diminished and yet the "index" may be as great or even greater than on the non-alkali days. This denotes a large excretion of acetone bodies combined with the alkali, which has temporarily lessened the need for the large ammonia production. On these days the comparison of ammonia values and the "acidosis index" indicates the extent to which we have been able to replace ammonia by the ingested alkali.

\section{QUANTITATIVE VALUE OF THE ACIDOSIS INDEX}

After observing the remarkable correspondence between the total acidosis accurately estimated and the "acidosis index" (see Chart 4), one is tempted to assign a quantitative value to the "acidosis index" (acidosis index $1=1$ gram oxybutyric acid). This is the only case in which I have carried out a series of observations of the "acidosis index" checked by the total acidosis estimated by this method; but a few other isolated observations made in the same way tend to corroborate this value.

Moreover, Table 4 , based on some 83 observations in fifteen individual cases, lends weight to this view.

Table 4.-Acidosis Index in 15 Cases, from 83 Observations

$\begin{array}{cccc}\begin{array}{c}\text { Acidosis } \\ \text { Index. }\end{array} & \begin{array}{c}\text { Ammonia } \\ \text { 24ours-grams } \\ \text { Averages. }\end{array} & \begin{array}{c}\text { Ammonia } \\ \text { Acidosis } \\ \text { Index. }\end{array} & \begin{array}{c}\text { 24 Hours-grams } \\ \text { Averages. }\end{array} \\ 2 & 1.123 & 12 & 3.500 \\ 5 & 1.375 & 13 & 4.335 \\ 7 & 2.303 & 17 & 4.487 \\ 8 & 2.960 & 20 & 4.634 \\ 9 & 3.474 & 23 & 4.760 \\ 10 & 3.424 & 25 & 5.790 \\ & 3.525 & 35 & 7.056\end{array}$

Table 5.-Ammoxia Equivalents for acidosis

\begin{tabular}{cccc} 
& \multicolumn{3}{c}{ Ammonia-Grams } \\
\cline { 2 - 4 } Oxybutyric Acid & To Neutralize & From Food. & Total. \\
gm. & Acid. & 1.5 & 2.5 \\
6 & 1 & 1.5 & 3.5 \\
12 & 2 & 1.5 & 4.5 \\
18 & 3 & 1.5 & 5.5 \\
24 & 4 & 1.5 & 6.5 \\
30 & 5 & 1.5 & 7.5
\end{tabular}

In constructing Table 4, only those days were selected on which the patients were getting no alkali. The figures are for the most part averages. For example: In nine instances, each showing an "acidosis index" of 7 , the ammonia output averaged $2.960 \mathrm{gm}$. If we assume that the high proteid diet of these days furnished $1.5 \mathrm{gm}$. of ammonia and that each. 
additional gram of ammonia represents an acidosis of $6 \mathrm{gm}$. of oxybutyric acid, ${ }^{10}$ we would obtain the values shown in Table 5 .

If these figures are compared with those of Table 4, it will be seen that there is a very close similarity in the ammonia equivalent for an acidosis represented by a given amount of oxybutyric acid and the corresponding figures of the "acidosis index." When we recall, however, that the method of obtaining the "acidosis index" depends on the color reaction of diacetic acid, and that the relative amount of diacetic acid varies greatly, ${ }^{11}$ inferences as to its quantitative value should be assumed with great caution and only after a much greater number of comparisons between the total acidosis (chemically determined by the more accurate methods) and the "acidosis index" have been made.

I think, however, that we are safe in concluding from the above studies that the "acidosis index" is of much value in following the daily fluctuations of the organic acid output, affording information well worth the three or four minutes necessary for its acquisition.

\section{CONCLUSIONS}

1. The "acidosis index" is a measure of acidosis based on the depth of color obtained with the ferric chlorid reaction.

2. The values thus obtained run parallel with the degree of acidosis estimated by (a) the polariscopic method, (b) ammonia output, (c) chemical determination of the acetone bodies.

3. It is probably a better measure of acidosis than the polariscopic method.

4. It is a more accurate measure of acidosis during the administration of alkalis than the estimation of ammonia, and is a valuable complement to the estimation of ammonia.

5. It is a simple clinical means of following the daily fluctuations of the organic acid excretion.

6. The value of the information gained from a knowledge of this "acidosis index" is well worth the expenditure of the few minutes necessary for its acquisition.

130 West Fifty-Ninth Street.

10. Magnus Levy: Arch. f. exper. Path. u. Pharmakol., 1901, xlv, 389.

11. Hart: Jour. Biol. Chem., 1908, iv, 476. 